DOI: $10.17805 /$ trudy.2016.6.5

\title{
ЗНАЧЕНИЕ ПРАКТИК В ФОРМИРОВАНИИ ОБЩЕКУЛЬТУРНЫХ И ОБЩЕПРОФЕССИОНАЛЬНЫХ КОМПЕТЕНЦИЙ У ОБУЧАЮЩИХСЯ ПО ПРОГРАММАМ МАГИСТРАТУРЫ
}

\author{
Е. Е. Иванова \\ (Московский гуманитарный университет)
}

\begin{abstract}
Аннотация: В статье рассматривается роль и значение практики 8 формировании общекультурных и общепрофессиональных компетенций у выпускников вузов по направлению подготовки «Психолого-педагогическое образование» (уровень магистратуры). Анализируются функции и пути оптимизации содержания учебной и производственной практик.

Ключевые слова: учебная практика; производственная практика; общепрофессиональная компетентность; личностно-ориентированный подход; вариативность; образовательный процесс; магистратура
\end{abstract}

\section{THE ROLE OF INTERNSHIP IN BUILDING CULTURAL AND VOCATIONAL COMPETENCIES OF STUDENTS IN MASTER'S DEGREE PROGRAMS}

\author{
E. E. Ivanova \\ (Moscow University for the Humanities)
}

Abstract: The article examines the role internship plays in developing common cultural and general vocational competencies of university graduates who majored in' psychological and pedagogical education' (master's level). Also analyzed are the functions and ways of optimizing the content of internship at educational institutions and industrial enterprises.

Keywords: teaching internship; industrial placement; professional competence; personality-focused approach; variability; educational process; master's degree program

Содержание обучения магистрантов по направлению подготовки «Психолого-педагогическое образование» включает в себя фундаментальную педагогическую и психологическую подготовку к работе в однойдвух сферах профессиональной деятельности. В этих условиях будущим магистрам сложно приобрести опыт самостоятельных решений реальных профессиональных задач и применить в полной мере полученные 
теоретические знания. В результате нередко проявляется практическая неприспособленность выпускников магистратуры к условиям конкретной профессиональной деятельности, затруднения в решении профессиональных задач. Во многих случаях молодые специалисты демонстрируют недостаточную операциональную готовность к профессиональной деятельности.

Выходом из данной ситуации может стать совершенствование содержания практики, являющейся важнейшей составляющей образовательного процесса в формировании и развитии общепрофессиональной компетентности.

Особое значение практики определяется тем, что в ходе ее прохождения у будущих магистров должны сложиться объективные представления о специфике и особенностях профессиональной деятельности, о перспективах своего развития в современных общественно-экономических условиях.

Для формирования таких представлений необходимо выполнение ряда условий:

- придание образовательному процессу практикоорентированного характера в течение всего периода обучения;

- практика должна рассматриваться как постоянная составляющая учебно-профессиональной деятельности, направленной на актуализацию у магистрантов саморазвития и формирование общепрофессиональной компетентности;

- должна быть разработана и внедрена педагогическая модель развития профессиональной компетентности будущих магистров, отражающая специфику образовательной программы.

Определение содержания практики на современном этапе - объективная потребность времени и требования ФГОС 3+.

Именно потребностями и запросами общества руководствовались научно-педагогические работники кафедры педагогики и психологии высшей школы, когда разрабатывали образовательную программу «Педагогический менеджмент», и ориентировались на организационноуправленческий и научно - исследовательский вид деятельности.

В действующем ФГОСе 3+ по направлению подготовки 44.04.02 «Психолого-педагогическое образование» выпускник, освоивший программу магистратуры, в соответствии с ведущим видом деятельности должен быть подготовлен к решению следующих профессиональных задач:

- в области научно-исследовательской деятельности магистрант должен иметь опыт изучения, анализа и обобщения результатов российских и зарубежных научных исследований в области психолого-педагогического образования с целью определения проблем научного исследования; 
проектирование и реализация НИР и опытно-конструкторской работы, научно-исследовательских и социальных проектов в сфере образования; анализировать и обобщать результаты исследовательских, развивающих, педагогических и иных социальных проектов в психолого-педагогической области; осуществление экспертизы образовательных проектов с точки зрения их соответствия возрастным возможностям обучающихся и соответствия современным научным психологическим подходам в возрастной, педагогической и социальной психологии;

- в области организационно-управленческой деятельности магистрант должен решать задачи, связанные с развитием организации, осуществляющей образовательную деятельность, в соответствии с разработанными планами и программами развития организации; иметь опыт разработки эффективной организационной модели деятельности организации, осуществляющей образовательную деятельность, обеспечения условия для создания комфортной среды организации, осуществляющей образовательную деятельность, организации внутриведмственного и межведомственного взаимодействия; участвовать в разработке совместно с педагогическими работниками и учебно-вспомогательным персоналом организации, осуществляющей образовательную деятельность стратегий и планов развития организации, осуществляющей образовательную деятельность.

В соответствии с ФГОС 3+ по направлению подготовки 44.04 .02 «Психолого-педагогическое образование» выделены два вида практик: учебная и производственная, в том числе преддипломная практика. При этом отмечено, что тип учебной практики предполагает практику получения первичных профессиональных умений и навыков, а производственная практика связана с получением профессиональных умений и опыта профессиональной деятельности.

Вместе с тем в ФГОС 3+ указывается, что «при разработке программ магистратуры организация выбирает типы практик в зависимости от видов деятельности, на которые ориентирована программа магистратуры» (Утвержден ФГОС ..., 2016: Электронный ресурс). Следовательно, вуз имеет право самостоятельно установить и другие виды практик. Цели и задачи, программы и формы отчетности по которым определяются вузом по каждому виду практики.

Изучение вузовской практики показывает, что практика выполняет следующие функции:

адаптационную, которая проявляется в том, что обучающийся не только знакомится с разными видами учреждений и организацией работы, но и привыкает к ритму рабочего процесса, начинает ориентироваться в системе производственных отношений и связей; 
обучающую, которая направлена на выработку основных профессиональных умений, формирование профессионального сознания, которое из плоскости идеальных представлений переходит в систему реальных установок и взглядов;

воспитывающую, которая состоит в том, что будущий магистр может подготовиться к работе с людьми, выработать у себя терпение, выдержку, настойчивость, ответственность и чувство долга;

развивающую, которая позволяет формироваться и развиваться организаторским способностям;

диагностическую, которая дает возможность выявить личностные и профессиональные качества будущего магистра, его сильные и слабые стороны.

Учебная практика направлена на закрепление и конкретизацию результатов теоретического обучения; приобретение обучающимися умений и навыков практической работы по избранному направлению подготовки и присваиваемой квалификации.

Цель практики - научиться наблюдать, понимать и анализировать деятельность образовательной организации.

В задачи учебной практики входит:

- знакомство со спецификой организации деятельности;

- выделение основных направлений деятельности образовательной организации;

- изучение деятельности специалистов, отвечающих специфике образовательной программы, а также собственным профессиональным и научным интересам.

Проанализировав специфику деятельности образовательной организации, магистрантам необходимо определить противоречия между теорией и практикой в профессиональной деятельности отдельных специалистов, между уровнем профессионального развития специалиста и требованиями профессионального стандарта.

На заключительном этапе, задача магистрантов - конкретизировать существующие проблемы и предложить возможные пути, способы их устранения.

Производственная практика направлена на получение профессиональных умений и опыта профессиональной деятельности. Целью ее является - приобретение обучающимися необходимых педагогических и психолого-педагогических практических умений и их закрепление в условиях образовательной организации (школа, колледж или вуз), а также развитие профессионального мировоззрения, профессиональной рефлексии и личностно-профессиональных качеств, необходимых в психолого-педагогической деятельности, в соответствии с требованиями 
профессионального стандарта педагога-психолога.

Программа производственной практики ориентирована на включение магистрантов в самостоятельную деятельность, связанную с выявлением и анализом педагогического опыта, на подготовку к эффективному проведению профессиональных мероприятий, на формирование творческого подхода к решению профессиональных задач, интереса к научноисследовательской и учебно-методической работе.

Основной формой практики является непосредственное участие магистрантов в рабочем процессе кафедры и университета: знакомство с документацией с целью выявления особенностей направления работы, специфики должностных обязанностей и функций сотрудников кафедры, деканата, разных типов образовательной организации; знакомство с образовательными стандартами; с правилами ведения преподавателем отчетной документации; с рабочими программами учебных дисциплин, иной методической документацией.

В ходе практики магистранты участвуют в научно-методических мероприятиях университета, факультета и кафедры; в обсуждении профессорско-преподавательским составом кафедры создания рабочих программ дисциплин и разработки фонда оценочных средств, других методических материалов; оказывают помощь в анализе рабочих программ, написании экспертных заключений, рецензий на рабочие программы учебных дисциплин.

В соответствии с требованиями ФГОС 3+ по направлению подготовки «Психолого-педагогическое образование» в производственную практику включается преддипломная практика.

Целью этой практики является приобретение навыков владения современными методами и принципами разработки научной проблематики по теме магистерской диссертации; ориентация на целевое овладение современными методами поиска, обработки и использования научной информации; творческий анализ научной и научно-методической литературы для развития умений трансляции знаний; освоение умений ставить цели, формировать задачи индивидуальной и совместной деятельности.

Таким образом, основная идея практики заключается в формировании и развитие профессионального мышления, необходимых общекультурных и общепрофессиональных знаний, навыков, умений и опыта, способствующих процессу социализации личности, усвоению общественных норм, ценностей профессии, а также формированию деловой культуры магистранта. 


\section{СПИСОК ЛИТЕРАТУРЫ}

Утвержден ФГОС ВО по направлению подготовки 44.04.02 Психологопедагогическое образование (далее соответственно - программа магистратуры, направление подготовки) (2016) [Электронный ресурс] // Координационный совет Учебно-методических объединений и учебнометодических советов высшей школы. 1 июня. URL: http://gosvo.ru/ news/4/1868 (дата обращения: 12.11.2016).

Дата поступления: 12.12.2016 г.

Иванова Екатерина Евгеньевна - кандидат психологических наук, доцент кафедры педагогики и психологии высшей школы Московского гуманитарного университета. Адрес: 111395, Россия, г. Москва, ул. Юности, д. 5. Тел.: +7 (499) 374-74-59. Эл. адрес: katriniva@mail.ru

Ivanova Ekaterina Evgenievna, Candidate of Psychology, Associate Professor, Department of Pedagogy and Psychology of Higher school, Moscow University for the Humanities. Postal address: 5 Yunosti St., 111395 Moscow, Russian Federation. Tel.: +7 (499) 374-74-59. Эл. адрес: katriniva@mail.ru

\section{Для циитирования:}

Иванова Е. Е. Значение практик в формировании общекультурных и общепрофессиональных компетенций у обучающихся по программам магистратуры [Электронный ресурс] // Научные труды Московского гуманитарного университета. 2016, № 6. URL: http://journals.mosgu.ru/trudy/article/view/377 (дата обращения: дд.мм.гг.). 